\title{
Endometrial patterns in abnormal uterine bleeding: a retrospective study
}

\author{
Sajeetha Kumari R.*, Anuradha M.
}

Department of Obstetrics and Gynecology, SRM Medical College and Research Centre, Kattankulathur, Kancheepuram, Tamil Nadu, India

Received: 20 August 2017

Accepted: 16 September 2017

\section{*Correspondence:}

Dr. Anuradha M.,

E-mail: ogsrmmch@gmail.com

Copyright: () the author(s), publisher and licensee Medip Academy. This is an open-access article distributed under the terms of the Creative Commons Attribution Non-Commercial License, which permits unrestricted non-commercial use, distribution, and reproduction in any medium, provided the original work is properly cited.

\begin{abstract}
Background: Abnormal uterine bleeding (AUB) is a common reason for women of all ages to consult their gynecologist and is one of the most common debilitating menstrual problems ending up in hysterectomy in developing countries. The aim of the present study was to determine the clinical spectrum and frequency of pathologies in endometrial biopsy of patients with AUB in our population. We also tried to observe the incidence of various pathologies in different age groups presenting with abnormal uterine bleeding.

Methods: The study was conducted in SRM Medical College Hospital and Research Centre, Tamil Nadu over a period of eight months. This was a retrospective study done on 217 patients presenting with abnormal uterine bleeding who underwent endometrial sampling in our hospital. The pattern of endometrial changes were studied and classified.

Results: Age of the patients in our study ranged from 25 years to 68 years with maximum in the age group of 41-50 years. The commonest clinical feature was menorrhagia followed by metrorrhagia. Evaluation of the endometrium revealed various histopathological patterns like proliferative endometrium, secretory endometrium, disordered proliferative endometrium, pill endometrium, shedding endometrium, simple hyperplasia, complex hyperplasia, atrophic endometrium, endometrial polyp, carcinoma endometrium etc. The incidence of malignancy was $1.84 \%$.

Conclusions: Histopathological examination of the endometrium showed a wide spectrum of pathological changes ranging from normal endometrium to malignancy thus emphasizing the importance of endometrial sampling as an important diagnostic tool in the management of abnormal uterine bleeding. Accurate analysis of endometrial samplings is the key to effective therapy and optimal outcome.
\end{abstract}

Keywords: Abnormal uterine bleeding, Dilatation and curettage, Endometrium, Histopathology

\section{INTRODUCTION}

Menstruation is a very complex process involving oestrogen and progesterone and their receptors, endometrial vasculature, endometrial vasoactive substances, processes of tissue break down and remodelling and endometrial repair and regeneration. Abnormal Uterine Bleeding (AUB) is defined as any bleeding that does not correspond with the frequency, duration or amount of blood flow of a normal menstrual cycle and could be a sign of simple hormonal imbalance or a serious underlying condition necessitating aggressive treatment including a major surgical procedure.

It affects $10-30 \%$ of reproductive aged women and upto $50 \%$ of perimenopausal women. ${ }^{1}$ Pattern and causes of abnormal uterine bleeding differs in different age group and reproductive status of women. Abnormal uterine 
bleeding is a common reason for women of all ages to consult their gynaecologist and is one of the most common debilitating menstrual problems that has remained one of the most frequent indications for hysterectomy in developing countries. ${ }^{2}$ It includes both organic and inorganic causes. The most common presentations are menorrhagia, polymenorrhoea, metrorrhagia and intermenstrual bleeding.

Since endometrium is the best accessible tissue for histopathological evaluation of uterine bleeding, several methods are used for endometrial sampling among which Dilatation and Curettage is used as standard practice in our set up. The aim of the present study was to determine the clinical spectrum and frequency of pathologies in endometrial biopsy of patients with AUB in our population. We also tried to observe the incidence of various pathologies in different age groups presenting with abnormal uterine bleeding.

\section{METHODS}

This was a retrospective study carried out in the Department of Obstetrics and Gynecology, SRM Medical College Hospital and Research Centre, Kattankulathur, Tamil Nadu from November 2015 to June 2016 for a period of 8 months. All women in the age group of 19 years and above who had presented with abnormal uterine bleeding and had undergone endometrial biopsy or curettage were included in the study. Women with pregnancy complications, thyroid disorders and coagulation disorders were excluded from the study.

217 women with abnormal uterine bleeding who had undergone endometrial curettage or biopsy who satisfied the inclusion criteria were selected. Data on the age, presenting clinical feature, procedure done and the histopathological report were retrieved using records from gynecology OPD, gynecology ward, operation notes, patient case sheets and pathology reports. Age, pattern of bleeding, duration of abnormal uterine bleeding and observed histopathological spectrums were recorded and classified.

Various endometrial patterns were classified as follows: Proliferative, Secretory, Atrophic, Unsatisfactory, Chronic Endometritis, Polyp, Hyperplasia and Carcinoma. Endometrial Hyperplasia was classified according to World Health Organization (WHO), originally proposed by Kurman and Norris, into simple and complex on the basis of architecture and each was further subdivided into typical and atypical, based on cytology. Data was collected and analyzed. Analysis was done in the form of percentage and represented as tables and figures where necessary.

\section{RESULTS}

A total of 217 patients were included in the study. The patients were categorized into five groups based on their age. Age of the patients in our study ranged from 25 years to 68 years with a mean of 47 years. Maximum patients with abnormal uterine bleeding presented in the age group of 41-50 years and the predominant pattern was proliferative changes which were followed by disordered proliferative changes. Many participants presented with menorrhagia which was the most common clinical feature followed by metrorrhagia. The presenting clinical patterns of these patients are summarized in table (Table 1).

Table 1: Pattern of bleeding in abnormal uterine bleeding.

\begin{tabular}{|lllllll|}
\hline Pattern of bleeding & 30 years or less & $31-40$ years & $\mathbf{4 1 - 5 0}$ years & $51-60$ years & $\mathbf{6 0}$ years or more & Total \\
\hline Menorrhagia & 5 & 33 & 55 & 2 & - & $95(43.78 \%)$ \\
\hline Metrorrhagia & 2 & 15 & 23 & - & - & $40(18.43 \%)$ \\
\hline Polymenorrhea & 1 & 4 & 4 & - & - & $9(4.15 \%)$ \\
\hline Polymenorrhagia & 2 & 9 & 17 & - & - & $28(12.9 \%)$ \\
\hline Continuous bleeding & 3 & 6 & 10 & - & - & $19(8.75 \%)$ \\
\hline Postmenopausal & - & - & 6 & 12 & 8 & $26(11.98 \%)$ \\
\hline Total & 13 & 67 & 115 & 14 & 8 & $217(100 \%)$ \\
\hline
\end{tabular}

Evaluation of the endometrium revealed various histopathological patterns like proliferative endometrium, secretory endometrium, disordered proliferative endometrium, pill endometrium, shedding endometrium, simple hyperplasia, complex hyperplasia, atrophic endometrium, endometrial polyp, carcinoma endometrium etc. Endometrial pathologies were observed in 48 patients whereas 162 patients had physiological patterns. In 7 cases, the endometrial curettings were scanty and inadequate for any diagnostic opinion. Among the physiological patterns proliferative changes were most common followed by disordered proliferative changes.

Among the pathological patterns, simple hyperplasia was most common. Hyperplasia was noted in 36 patients out of which 32 were simple hyperplasia and 4 were complex hyperplasia. 1 patient had atypical changes. There were 4 
cases of endometrial carcinoma and 5 cases of endometrial polyp. All cases of endometrial carcinoma were adenocarcinoma, out of which 3 patients had risk factors like obesity and diabetes mellitus.

Table 2: Endometrial pattern in abnormal uterine bleeding.

\begin{tabular}{|lllllll|}
\hline Endometrial patterns & $\begin{array}{l}\text { 30 years } \\
\text { or less }\end{array}$ & $\mathbf{3 1 - 4 0 \text { years }}$ & $\mathbf{4 1 - 5 0 \text { years }}$ & $\begin{array}{l}\mathbf{5 1 - 6 0} \\
\text { years }\end{array}$ & $\begin{array}{l}\text { 60 years } \\
\text { or more }\end{array}$ & Total \\
\hline Proliferative & $3(4.76 \%)$ & $11(17.46 \%)$ & $46(73.01 \%)$ & $2(3.17 \%)$ & $1(1.59 \%)$ & $63(29.03 \%)$ \\
\hline Secretory & $2(7.41 \%)$ & $12(44.44 \%)$ & $13(48.15 \%)$ & - & - & $27(12.44 \%)$ \\
\hline Disordered proliferative & $4(8.33 \%)$ & $17(35.42 \%)$ & $23(47.92 \%)$ & $4(8.33 \%)$ & - & $48(22.12 \%)$ \\
\hline Pill endometrium & - & $3(50 \%)$ & $3(50 \%)$ & - & - & $6(2.76 \%)$ \\
\hline Shedding & $2(14.29 \%)$ & $5(35.71 \%)$ & $7(50 \%)$ & - & - & $14(6.45 \%)$ \\
\hline Simple hyperplasia & - & $14(43.75 \%)$ & $15(46.88 \%)$ & $3(9.38 \%)$ & - & $32(14.75 \%)$ \\
\hline $\begin{array}{l}\text { Complex hyperplasia without } \\
\text { atypia }\end{array}$ & - & - & $2(66.67 \%)$ & - & $1(33.33 \%)$ & $3(1.38 \%)$ \\
\hline $\begin{array}{l}\text { Complex hyperplasia with } \\
\text { atypia }\end{array}$ & - & - & $1(100 \%)$ & - & - & $1(0.46 \%)$ \\
\hline Chronic endometritis & - & $3(100 \%)$ & & - & - & $3(1.38 \%)$ \\
\hline Atrophic & - & & $1(25 \%)$ & $2(50 \%)$ & $1(25 \%)$ & $4(1.84 \%)$ \\
\hline Endometrial polyp & $2(40 \%)$ & $1(20 \%)$ & $2(40 \%)$ & - & - & $5(2.3 \%)$ \\
\hline Carcinoma endometrium & - & - & $1(25 \%)$ & - & $3(75 \%)$ & $4(1.84 \%)$ \\
\hline Scanty & - & $1(14.29 \%)$ & $1(14.29 \%)$ & $3(42.86 \%)$ & $2(28.57 \%)$ & $7(3.23 \%)$ \\
\hline Total & $13(5.99 \%)$ & $67(30.88 \%)$ & $115(53 \%)$ & $14(6.45 \%)$ & $8(3.69 \%)$ & 217 \\
\hline
\end{tabular}

There were 7 samples of scanty endometrium mainly in the postmenopausal age group. The various histopathological patterns are shown in table (Table 2).

\section{DISCUSSION}

AUB is the overarching term used to describe any departure from normal menstruation or from a normal menstrual cycle pattern. ${ }^{3}$

Abnormal uterine bleeding is one of the most frequently encountered conditions in gynecology world over. AUB is of concern as it can have serious medical and social consequences by causing anemia, disruption of women's daily activities and sexual life.

In normal cycles, the menstrual shedding is followed by endometrial proliferation under estrogenic stimulation. During this phase the endometrial glands grow and become tortuous.

The secretory activity in the second half of the menstrual cycle is characterised by endothelial proliferation, thickening of the wall, and coiling of the spiral arterioles.

Our study received maximum number of cases from the perimenopausal age group which is comparable to the studies carried out by Vaidya et al, Agrawal et al and Salvi et al. ${ }^{4-6}$ But literature have mentioned studies where majority of cases were from the reproductive age group. ${ }^{7,8}$ Age was directly associated with the type of lesion,as more progressive lesions were observed in the perimenopausal and postmenopausal age group. The commonest age group presenting with excessive bleeding in our study was 41-50 years. A similar incidence was reported by Doraiswami et al, Yusuf et al and Muzaffar et al. ${ }^{9-11}$ This may be due to the fact that these women are in their climacteric phase when they tend to become anovulatory due to decline in the number of ovarian follicles and the estradiol level.

A significant number of cases in this study showed normal physiologic patterns like proliferative, secretory and atrophic endometrium. Bleeding in the proliferative phase may be due to anovulatory cycles and bleeding in secretory phase is due to ovulatory dysfunctional uterine bleeding. We found that the most common histopathological finding was prolierative endometrium in 63 cases (29\%).Similar findings were also noted by Khare et al (26.8\%), Saera et al (34.6\%), Anuradha Salvi et al $(37.2 \%)$ and Agarwal et al. ${ }^{5-8}$

A significant number of cases showed disordered proliferative endometrium in present study - 48 cases $(22.12 \%)$. This was slightly more when compared with the findings of Bashir $\mathrm{H}$ et al and Vaidya et al which showed $12.17 \%$ and $13.4 \%$ respectively. ${ }^{12,4}$ Disordered proliferative endometrium was commonly seen in perimenopausal age group similar to study of Doraiswami et al. ${ }^{9}$ It denotes an endometrial appearance that is hyperplastic but without an increase in endometial volume.There is no significant increase in the overall 
ratio of glands to stroma. ${ }^{13}$ It resembles a simple hyperplasia, but the process is focal rather than diffuse.

Irregular shedding of the endometrium is apparently due to slow degeneration of the corpus luteum with prolonged exposure to progesterone. Clinically, it manifests as cyclic prolonged menstruation. In present study, the total number of cases with shedding endometrium were 14 $(6.45 \%)$. This correlated with the findings of Baral R and Pudasaini S. ${ }^{13}$

In present study, the most common pathological cause for abnormal bleeding was endometrial hyperplasia (16.5\%). This is in consistent with the studies of Mirza et al, Anwer $\mathrm{M}$ et al in Karachi and Mogal N. ${ }^{14-16}$ Endometrial hyperplasia is a precursor of malignancy. It is a common diagnosis in perimenopausal women often causing symptoms of irregular or prolonged bleeding. This is due to increased oestrogen levels. The overgrowth affects not only glands and stroma but there is also abnormal vascularisation. ${ }^{12}$ The incidence of endometrial hyperplasia in our study was similar with the findings of Muzzafar et al which showed $18.3 \% .^{11}$ Majority of the cases of hyperplasia were simple hyperplasia and women were in the perimenopausal age group.Many studies have showed a similar increased incidence in perimenopausal age group..$^{9,11,17,18}$

Malignancy was seen in $4(1.8 \%)$ cases in our study. Studies by Muzzaffar $\mathrm{M}$ et al and Mirza $\mathrm{T}$ et al showed the incidence of malignancy to be $0.4 \%$ and $5 \%$ respectively. ${ }^{11,14}$ Most of the studies found majority of cases of malignancy in the postmenopausal age group. ${ }^{19,20}$ The main histopathological variant in present study was adenocarcinoma.

Endometrial polyp was seen in 5 cases in our series (2.3\%). Studies by Baral R and Zeeba et al showed an incidence of $1.3 \%$ and $1.7 \%$ respectively. ${ }^{13,18}$ Polyp was observed mainly in the perimenopausal and reproductive age group than the postmenopausal age group. This was in contrast with the study of Mariam Abid et al who showed an increased incidence of endometrial polyps in perimenopausal and post menopausal age group. ${ }^{2}$ None of the polyps in our study showed atypical changes.

We observed 4 cases of atrophic endometrium and all patients were in the postmenopausal age group. Anovulation in these women manifest as atrophic or inactive endometrium. Mechanism of bleeding due to atrophic endometrium in old age is stated in different studies as sclerotic degeneration of vessel wall or local abnormal haemostatic mechanism. This accounted for $1.8 \%$ of total cases. This was similar to the findings of Zeeba et al. ${ }^{18}$ Authors in discordance with this had reported $2.4 \%$ and $7 \% .^{9,14}$

There were $3(1.4 \%)$ cases of chronic endometritis which was seen in the age group of 31-40 years. This was much low when compared to many other studies. ${ }^{17,21-23}$ The diagnosis of chronic endometritis is made on the basis of the presence of plasma cells. ${ }^{20}$

\section{CONCLUSION}

Abnormal uterine bleeding is a common diagnosis and the commonest presentation is menorrhagia. Histopathological examination of the endometrium showed a wide spectrum of pathological changes ranging from normal endometrium to malignancy thus necessitating endometrial sampling as an important diagnostic tool in the management of abnormal uterine bleeding. Accurate analysis of endometrial sampling is the key to effective therapy and optimal outcome. This would help in individualizing the management of abnormal uterine bleeding with a view to conserve the uterus.

\section{ACKNOWLEDGMENTS}

The authors acknowledge the helping rendered by Dr. Revathi, Department of Obstetrics and Gynecology in data collection.

\section{Funding: No funding sources \\ Conflict of interest: None declared \\ Ethical approval: Not required}

\section{REFERENCES}

1. Sedhai LB, Shrestha A. Abnormal uterine bleeding; its prevalence, causes and management in Chitwan. $\mathbf{J}$ Chitwan Med Coll. 2012;1(2):36-38.

2. Abid M, Hashmi AA, Malik B, Haroon S, Faridi N, Edhi MM, Khan M. Clinical pattern and spectrum of endometrial pathologies in patients with abnormal uterine bleeding in Pakistan: need to adopt a more conservative approach to treatment. BMC Women's Health. 2014 Nov 5;14(1):132.

3. Fraser IS, Critchley HO, Broder M, Munro MG. The FIGO recommendations on terminologies and definitions for normal and abnormal uterine bleeding. InSeminars Reproductive Medicine. 2011;29(05):383-390).

4. Vaidya S, Lakhey M, Vaidya Amatya S, Sharma P K, Hirachand S, Lama S et al. Histopathological pattern of abnormal uterine bleeding in endometrial biopsies. Nepal Med Coll J. 2013;15(1):74-77.

5. Agrawal S, Mathur A, Vaishnav K. Histopathological study of endometrium in abnormal uterine bleeding women of all age groups in Western Rajasthan (400 cases). Int J Basic Appl Sci. 2014;4(3):15-18.

6. Salvi A, Mital P, Hooja N, Batar A, Soni P, Beniwal R. Spectrum of endometrial histopathology in women presenting with abnormal uterine bleeding. Sch J App Med Sci. 2015;3(1A):1-4.

7. Khare A, Bansal R, Sharma S, Elhence P, Makkar N, Tyagi Y. Morphological spectrum of Endometrium 
in patients presenting with dysfunctional uterine bleeding. People's J Scient Res. 2012;5(2):13-16.

8. Afghan S, Yasmeen A. Abnormal Uterine Bleeding (AUB) A Clinicopathological Study of 150 cases. Ann Pak Inst Med Sci. 2013;9(4):201-4.

9. Doraiswami S, Johnson $\mathrm{T}$, Rao S, Rajkumar A, Vijayaraghavan J, Panicker VK. Study of endometrial pathology in abnormal uterine bleeding. J Obstet Gynaecol India 2011;61(4):426-430.

10. Yusuf NW, Nadeem R, Yusuf AW. Dysfunctional uterine bleeding. A retrospective clinicopathological study over 2 years. Pak J Obstet Gynecol. 1996;9:2730 .

11. Muzaffar M, Akhtar KAK, Yasmin S, Mahmood-UrRehman, Iqbal W, Khan MA. Menstrual irregularities with excessive blood loss: a clinicopathologic correlation. J Pak Med Assoc. 2005;55:486-9.

12. Bashir H, Bhat N, Khuroo MS, Reshi R, Nazeir MJ, Qureshi MZ. Clinicopathological study of endometrium in patients with abnormal uterine bleeding. Int J Cur Res Rev. 2015 Nov 15;7(22):67.

13. Baral R, Pudasaini S. Histopathological pattern of endometrial samples in abnormal uterine bleeding. J Pathol Nepal. 2011;1(1):13-6.

14. Mirza T, Akram S, Mirza A, Aziz S, Mirza T, Mustansar T. Histopathological pattern of abnormal uterine bleeding in endometrial biopsies. J Basic Appl Sci. 2012;8:114-7.

15. Anwer M, Imdad SK, Jamal Q. Histpathological correlation of endometrial curettage with abnormal uterine bleeding pattern. J Surg Pak 2004;9(2):21-4.

16. Mogal N. Diagnostic value of endometrial curettage in abnormal uterine bleeding-a histopathological study. J Pak Med Assoc. 1997;47(12):295-9.

17. Abdullah LS, Bondagji NS. Histopathological pattern of endometrial sampling performed for abnormal uterine bleeding. Bahrain Med Bull. 2011;33(4):1-6.

18. Jairajpuri ZS, Rana S, Jetley S. Atypical uterine bleeding-Histopathological audit of endometrium A study of 638 cases. Al Ameen J Med Sci. 2013;6(1):21-8.

19. Prajapati R, Daveshwar MR. A clinic-pathological correlation of endometrial pattern in patients with abnormal uterine bleeding (Aub). Int J Res Med. 2015;4(2):128-32.

Cite this article as: Kumari SR, Anuradha M.

Endometrial patterns in abnormal uterine bleeding: a retrospective study. Int J Reprod Contracept Obstet Gynecol 2017;6:4966-70. 